PREPARED FOR THE U.S. DEPARTMENT OF ENERGY, UNDER CONTRACT DE-AC02-76CH03073

PPPL-3865

PPPL-3865

UC-70

Comparison of Linear Microinstability Calculations of Varying Input Realism

by

G. Rewoldt and J.E. Kinsey

September 2003

NM|

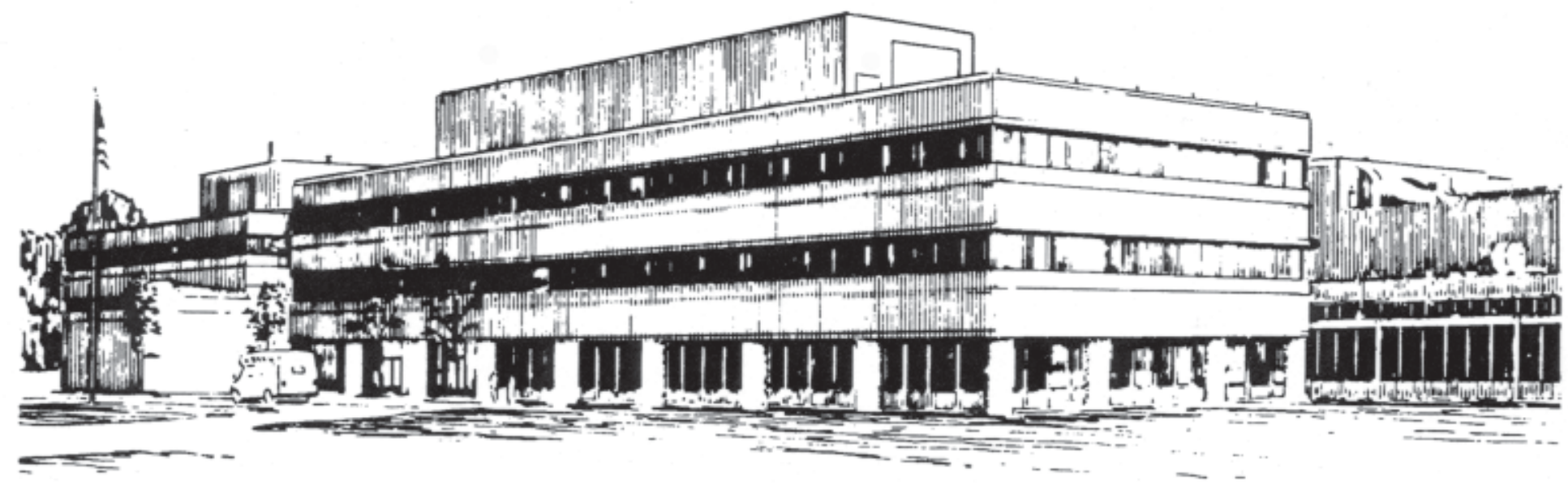

PRINCETON PLASMA PHYSICS LABORATORY PRINCETON UNIVERSITY, PRINCETON, NEW JERSEY 


\section{PPPL Reports Disclaimer}

This report was prepared as an account of work sponsored by an agency of the United States Government. Neither the United States Government nor any agency thereof, nor any of their employees, makes any warranty, express or implied, or assumes any legal liability or responsibility for the accuracy, completeness, or usefulness of any information, apparatus, product, or process disclosed, or represents that its use would not infringe privately owned rights. Reference herein to any specific commercial product, process, or service by trade name, trademark, manufacturer, or otherwise, does not necessarily constitute or imply its endorsement, recommendation, or favoring by the United States Government or any agency thereof. The views and opinions of authors expressed herein do not necessarily state or reflect those of the United States Government or any agency thereof.

\section{Availability}

This report is posted on the U.S. Department of Energy's Princeton Plasma Physics Laboratory Publications and Reports web site in Fiscal Year 2003. The home page for PPPL Reports and Publications is: http://www.pppl.gov/pub_report/

DOE and DOE Contractors can obtain copies of this report from:

U.S. Department of Energy

Office of Scientific and Technical Information

DOE Technical Information Services (DTIS)

P.O. Box 62

Oak Ridge, TN 37831

Telephone: (865) 576-8401

Fax: (865) 576-5728

Email: reports@adonis.osti.gov

This report is available to the general public from:

National Technical Information Service

U.S. Department of Commerce

5285 Port Royal Road

Springfield, VA 22161

Telephone: $1-800-553-6847$ or

(703) $605-6000$

Fax: (703) 321-8547

Internet: http://www.ntis.gov/ordering.htm 


\title{
Comparison of linear microinstability calculations of varying input realism
}

\author{
G. Rewoldt* \\ Princeton Plasma Physics Laboratory, \\ Princeton University, Princeton, New Jersey 08543-0451 \\ J.E. Kinsey \\ General Atomics, P.O. Box 85608, San Diego, California 92186-5608
}

\begin{abstract}
The effect of varying "input realism" or varying completeness of the input data for linear microinstability calculations, in particular on the critical value of the ion temperature gradient for the ion temperature gradient mode, is investigated using gyrokinetic and gyrofluid approaches. The calculations show that varying input realism can have a substantial quantitative effect on the results.
\end{abstract}

PACS numbers: $52.35 . \mathrm{Qz}, 52.65 . \mathrm{Tt}, 52.55 . \mathrm{Fa}$ 
We want to determine the effects of going from more simplified input data to more "experimentally-realistic" input data, in particular on the marginally-stable critical value of the ion temperature gradient for the ion temperature gradient (ITG) mode. This work is in a sense an extension of that in Ref. 1 where a very specific simplified set of parameters (referred to as the basic Cyclone case), based on a discharge ${ }^{2}$ of the DIII-D tokamak, ${ }^{3}$ was specified for purposes of comparison of linear and nonlinear gyrokinetic and gyrofluid codes. Here, on the other hand, we examine the effects on this linear critical value of progressively adding back in the experimental realism that was omitted from the basic Cyclone case. To do this we employ the gyrokinetic code FULL ${ }^{4,5}$ and the gyrofluid code GLF23. ${ }^{6}$ Both of these codes are linear, radially-local (i.e., ballooning representation or flux tube) eigenvalue codes. They differ in that the FULL code solves for the eigenfunction along the unperturbed magnetic field line, whereas the GLF23 code prescribes a trial wavefunction along the field line. Since its original release, the trial wavefunction in GLF23 has been altered to include $\hat{s}$ and $\alpha$ dependence to better reproduce the growth rates for reversed magnetic shear internal transport barrier (ITB) parameters; the transport levels in the model were also recently renormalized using nonlinear gyrokinetic simulations. ${ }^{7}$

Here, we start with the basic Cyclone case as specified in Ref. 1. This case is collisionless, electrostatic, uses the $\hat{s}-\alpha$ model magnetohydrodynamic (MHD) equilibrium with $\alpha=0$ (no Shafranov shift), uses the experimental values of $T_{i}$ and $R / L_{T i} \equiv-R d \ln T_{i} / d r$ for both ions and electrons, includes only the adiabatic part of the electron response, and includes only the electron and background deuterium ion species.

Then we start adding in additional effects, in stages, to make the case progressively more realistic for the original DIII-D discharge ${ }^{2} 81499$ at $t=4.0 \mathrm{~s}$ and $r / a=0.5$, that the basic Cyclone case is based on.

For each stage, the critical value $\left(R / L_{T i}\right)^{\text {crit }}$ for marginal stability of the ITG mode is calculated, varying the temperature gradients of all species in proportion to $\left(R / L_{T i}\right)$, with the density gradients of all species and $k_{\theta} \rho_{i}=0.335$ (very close to the growth rate maximum for the basic Cyclone case) held fixed, where $k_{\theta} \equiv n q / r$ and $\rho_{i} \equiv \sqrt{T_{i} / m_{i}} /\left(e_{i} B_{0} / m_{i} c\right)$.

The results are summarized in Table I. For Case (a), which is the basic Cyclone case, the parameters are: $r / R=0.18, q=1.4, \hat{s}=0.776, \alpha=0, R / L_{n i}=R / L_{n e}=2.22$, $R / L_{T i}=R / L_{T e}=6.92$, and $T_{i} / T_{e}=1.0$, in standard notation. The FULL code result is $\left(R / L_{T i}\right)^{\text {crit }}=4.0$ and the GLF23 result is $\left(R / L_{T i}\right)^{\text {crit }}=4.5$, which are in reasonable 
agreement.

Then, Case (b) adds the collisionless trapped electron response to the calculation, which is destabilizing due to the collisionless trapped electron mode destabilization mechanism. This is a trapped electron toroidal precession drift resonance mechanism. The marginally stable values $\left(R / L_{T i}\right)^{\text {crit }}$ are thereby lowered to 3.1 for the FULL code and to 3.3 for the GLF23 code, in good agreement.

For Case (c), $\alpha \neq 0$ (i.e., the Shafranov shift is included); a carbon impurity species is added, but only by a dilution effect on the background deuterium ions; electron and ion and impurity collisions are included; and the experimental values of $T_{e}$ and $R / L_{T e}$ are used for the electrons. The new parameters are: $\alpha=0.3, R / L_{T e}=4.23, T_{i} / T_{e}=1.2, Z_{\mathrm{eff}}=2.3$ (dilution effect only), and $\nu_{e}^{*}=0.05$, with the other parameters the same as in Case (a). Each of these effects is somewhat stabilizing, and the overall result is to raise $\left(R / L_{T i}\right)^{\text {crit }}$ to 3.8 for the FULL code and 4.0 for the GLF23 code, again in good agreement. Case (c) is the most realistic case that can be calculated with the GLF23 code in its present form.

Finally, for Case $(\mathrm{d})$, which is calculated only by the FULL code, a finite- $\beta$ non-updown-symmetric MHD equilibrium, reconstructed numerically from the experiment by the EFIT code ${ }^{8}$ is used instead of the $\hat{s}-\alpha$ model MHD equilibrium. In addition for Case $(\mathrm{d})$, the complete response for the carbon impurity species is used, and the complete response for a hot deuterium beam species with a slowing-down equilibrium distribution function is added. The numerical MHD equilibrium has less bad curvature than the model MHD equilibrium, and thus weakens the collisionless trapped electron mode destabilization mechanism substantially, while the complete carbon response is moderately stabilizing, and the added hot beam species is essentially neutral for this case. The final result for Case (d) is $\left(R / L_{T i}\right)^{\mathrm{crit}}=5.4$.

For this Cyclone-DIII-D case, the most realistic value of $\left(R / L_{T i}\right)^{\text {crit }}=5.4$ is not very far from the experimental value $\left(R / L_{T i}\right)=6.92$, so that the the mode is not very far from marginal stability, and sheared $\mathbf{E} \times \mathbf{B}$ rotation may finish stabilizing the mode. The overall conclusion here is that changes in the "realism" of the input data can make substantial quantitative differences in the linear results, due to a combination of added stabilizing and destabilizing effects. This point is implicit in previous work on microinstabilities, but it is useful to make the point explicitly here, and it is important to keep it in mind for future global and nonlinear studies. In addition, any improvements in experimental measurements 
TABLE I: Results for $\left(R / L_{T i}\right)^{\text {crit }}$ for ITG root for cases of varying input realism

\begin{tabular}{lll}
\hline \hline Case & FULL $\left(R / L_{T i}\right)^{\text {crit }}$ & GLF23 $\left(R / L_{T i}\right)^{\text {crit }}$ \\
\hline
\end{tabular}

(a) Basic Cyclone

case: adiabatic

4.0

4.5

electrons

(b) Add

collisionless

3.1

3.3

trapped electrons

(c) Add $\alpha \neq 0$, carbon

(dilution only), collisions,

4.0

exper. $T_{e} \& R / L_{T e}$

(d) Add finite- $\beta$ non-up-down-symm.

EFIT MHD equil., complete carbon,

\& slowing-down hot beam species

of input profiles of density, temperature, and so on, and therefore of their gradients, will correspondingly improve the calculated results.

\section{Acknowledgments}

Th authors would like to thank Dr. C. Bolton for suggesting these calculations. This work was supported by U.S. DOE Contract Nos. DE-AC02-76-CHO-3073 and DE-AC0389ER51114.

\section{* rewoldt@pppl.gov}

1 A.M. Dimits, G. Bateman, M.A. Beer, et al., Phys. Plasmas 7, 969 (2000).

2 C.M. Greenfield, J.C. DeBoo, T.H. Osborne, F.W. Perkins, M.N. Rosenbluth, and D. Boucher, Nucl. Fusion 37, 1215 (1997).

3 J.L. Luxon, R. Anderson, F. Batty, et al., Plasma Physics and Controlled Nuclear Fusion Re- 
search, 1986 (International Atomic Energy Agency, Vienna, 1987), Vol. I, p. 159.

4 G. Rewoldt, W. M. Tang, and M. S. Chance, Phys. Fluids 25, 480 (1982).

5 G. Rewoldt, W. M. Tang, and R. J. Hastie, Phys. Fluids 30, 807 (1987).

6 R.E. Waltz, G.M. Staebler, W. Dorland, G.W. Hammett, M. Kotschenreuther, and J.A. Konings, Phys. Plasmas 4, 2482 (1997).

7 J.E. Kinsey, G.M. Staebler, and R.E. Waltz, "Burning Plasma Confinement Projections and Renormalization of the GLF23 Drift-wave Transport Model," to appear in Fus. Sci. and Tech.; Version 1.61 of GLF23 is employed in the present work.

8 L.L. Lao, J.R. Ferron, R.J. Groebner, W. Howl, H. St. John, E.J. Strait, and T.S. Taylor, Nucl. Fusion 30, 1035 (1990). 


\section{External Distribution}

Plasma Research Laboratory, Australian National University, Australia

Professor I.R. Jones, Flinders University, Australia

Professor João Canalle, Instituto de Fisica DEQ/IF - UERJ, Brazil

Mr. Gerson O. Ludwig, Instituto Nacional de Pesquisas, Brazil

Dr. P.H. Sakanaka, Instituto Fisica, Brazil

The Librarian, Culham Laboratory, England

Mrs. S.A. Hutchinson, JET Library, England

Professor M.N. Bussac, Ecole Polytechnique, France

Librarian, Max-Planck-Institut für Plasmaphysik, Germany

Jolan Moldvai, Reports Library, Hungarian Academy of Sciences, Central Research Institute for Physics, Hungary

Dr. P. Kaw, Institute for Plasma Research, India

Ms. P.J. Pathak, Librarian, Institute for Plasma Research, India

Ms. Clelia De Palo, Associazione EURATOM-ENEA, Italy

Dr. G. Grosso, Instituto di Fisica del Plasma, Italy

Librarian, Naka Fusion Research Establishment, JAERI, Japan

Library, Laboratory for Complex Energy Processes, Institute for Advanced Study, Kyoto University, Japan

Research Information Center, National Institute for Fusion Science, Japan

Dr. O. Mitarai, Kyushu Tokai University, Japan

Dr. Jiangang Li, Institute of Plasma Physics, Chinese Academy of Sciences, People's Republic of China

Professor Yuping Huo, School of Physical Science and Technology, People's Republic of China

Library, Academia Sinica, Institute of Plasma Physics, People's Republic of China

Librarian, Institute of Physics, Chinese Academy of Sciences, People's Republic of China

Dr. S. Mirnov, TRINITI, Troitsk, Russian Federation, Russia

Dr. V.S. Strelkov, Kurchatov Institute, Russian Federation, Russia

Professor Peter Lukac, Katedra Fyziky Plazmy MFF UK, Mlynska dolina F-2, Komenskeho Univerzita, SK-842 15 Bratislava, Slovakia

Dr. G.S. Lee, Korea Basic Science Institute, South Korea

Institute for Plasma Research, University of Maryland, USA

Librarian, Fusion Energy Division, Oak Ridge National Laboratory, USA

Librarian, Institute of Fusion Studies, University of Texas, USA

Librarian, Magnetic Fusion Program, Lawrence Livermore National Laboratory, USA

Library, General Atomics, USA

Plasma Physics Group, Fusion Energy Research Program, University of California at San Diego, USA

Plasma Physics Library, Columbia University, USA

Alkesh Punjabi, Center for Fusion Research and Training, Hampton University, USA

Dr. W.M. Stacey, Fusion Research Center, Georgia Institute of Technology, USA

Dr. John Willis, U.S. Department of Energy, Office of Fusion Energy Sciences, USA

Mr. Paul H. Wright, Indianapolis, Indiana, USA 
The Princeton Plasma Physics Laboratory is operated by Princeton University under contract with the U.S. Department of Energy.

\author{
Information Services \\ Princeton Plasma Physics Laboratory \\ P.O. Box 451 \\ Princeton, NJ 08543
}

Phone: 609-243-2750

Fax: 609-243-2751

e-mail: pppl_info@pppl.gov

Internet Address: http://www.pppl.gov 